\title{
The shortage of skilled workers in Europe: its impact on geriatric medicine
}

\author{
Jean-Pierre Michel $^{1}$ [ $\cdot$ Fiona Ecarnot ${ }^{2,3}$
}

Published online: 23 April 2020

(c) European Geriatric Medicine Society 2020

Keywords Health workforce $\cdot$ Healthcare professionals $\cdot$ Health workers $\cdot$ Education $\cdot$ Geriatrics

For a variety of reasons (...), countries are unable to educate and sustain the health workforce that would improve people's chances of survival and their wellbeing.

Dr LEE Jong-Wook.

Director-General World Health Organization 2006.

The Covid 19 pandemic has clearly revealed the importance of health, especially of the old and the vulnerable, as well as the crucial role played day and night, 24/7, 365 days a year, by healthcare professionals, namely all health workers engaged in activities whose primary intent is to enhance health. In the 28 countries of the European Union (EU28) in 2016, there were 6.43 million healthcare workers [1]. Among these, there were:

- 1.8 million physicians, $49 \%$ of whom were women, and among both genders, $38 \%$ were older than 55 years of age ( $55 \%$ in Italy versus $<15 \%$ in the United Kingdom) [2]. On average, there were 3.6 physicians per 1000 people.

- 2.8 million nurses [3], with a widely heterogeneous spread depending on the country, ranging from 0.86 nurses per 100,000 people in Romania to 11.56 in Luxemburg [4]. On average, there were 8.6 nurses per 1000 people.

In the EU28, there exists an unequal spread of practising doctors and nurses. Only Denmark, Germany and Sweden have more of both professionals, while Croatia, Estonia,

Jean-Pierre Michel

Jean-pierre.michel@unige.ch

1 Medical University of Geneva, Geneva, Switzerland

2 Department of Cardiology, University Hospital Besancon, Besançon, France

3 EA3920, University of Franche-Comté, Besançon, France
Hungary, Latvia, Poland, Romania, Slovakia and United Kingdom lack both physicians and nurses to varying degrees [5].

Again, in the EU28, the overall shortfall of health workers was estimated to be 1.6 million in 2013, which would require an average annual exponential growth above $2 \%$ to be compensated for [4]. As this rate of increase has not been reached, the expected shortage in the EU28 is anticipated to reach 4.1 million in 2030 (0.6 million physicians, 2.3 million nurses and 1.3 million other health care professionals) [4]. The 2030 demand for healthcare workers is estimated based on an economic model that includes projected economic growth, demographic trends, health coverage and health workforce data (1990-2013) established by the WHO Global Health Observatory for 165 countries [5].

This workforce shortage has several intricately linked causes. Internal reasons are closely related to the ageing of the workforce, difficult working conditions, poor lifelong learning, skill mismatches, weak career development and insufficient social recognition [6]. On the other hand, new consumer expectations are associated with changing demands for care, particularly the increasing number of old patients with chronic conditions, multimorbidity and disability $[7,8]$. This new care panorama was not well enough foreseen by health services, who did not adapt their models of care delivery in time $[9,10]$, neglecting workforce planning and emerging technological innovations [6]. According to a recent study, $82 \%$ of burn-out among global healthcare professionals is directly related to the health system organization and infrastructure enhancements [11].

The ability to attract more women and youth to work in the field of health is linked to inter-sectorial capacity-building, and to the policy actions of the Ministries of health, education, finance and labour in each European country [12]. Indeed, it will be important to reform the healthcare system, with more funding and creation of new jobs [13], but the impact will not be maximised without greater social 
recognition of all health and social professions-not only obstetrics and paediatrics, but also geriatrics/long term care, palliative care specialists, as well as nurses, nurses' aides, and basically all the professionals working in health and social care.

Moreover, it has been proven that early health education, starting in primary school and continuing along the whole educational pathway, has multiple positive effects. "The whole school, whole community, and whole child" model proved that children following this training have a better health education, which explains why they adopt better health behaviours, educate their family members and more often choose a career in healthcare [14]. Currently, across the scientific curriculum of all schools, technology takes an increasingly predominant place, which is logical and necessary, but the curricula do not include the study of the ageing process that affects all humans and animals. This is an ageist oversight!

In the university faculties dedicated to educating future health professionals, the totally separated programmes of dentistry, medicine, nursing, veterinary and other healthcare professionals very often neglect the "ageing process", which starts at conception, to end at death. Integrating the ageing process into any education programme would make it possible to teach genetics, nutrition, physiology, pathology amongst others, in a more dynamic and concrete way. This could also easily be linked with environmental conditions of life, philosophy, psychology, sociology, ethics and more. Accordingly, why not propose to these close, but distinct professional schools, a transversal teaching programme across the different courses? The benefits would be multiple: need for fewer teachers providing similar lectures, selection of the most expert teachers, exchanges between disciplines allowing health professionals to learn how to work together in an interdisciplinary way. Indeed, this approach would not by any means exclude the specific major training in dentistry, medicine, nursing, pharmacy and others, but would create a new community of health professionals who better understand the complementary roles they play in society. Moreover, inter-professional teaching would greatly benefit from the rapid development of education technology. Initiatives such as blended teaching [15], serious games [16], virtual patients [17], virtual team play [18] and very soon, machine learning [19] will totally transform the education of health professionals. Such fundamental changes are urgently needed to attract more young and promising learners of both genders into the field of health. Too often, students hesitate to enter training as healthcare professionals because they are afraid of the reputed difficulties of acquiring great amounts of knowledge, presented in an old-fashioned way, often in a very competitive environment, and in a manner that does not correspond to their way of anticipating their future role in society.
Being trained as a healthcare professional is one thing, but appreciating the chosen career enough to remain in the profession is another important aspect. As mentioned above, changing working conditions require constant updating of knowledge, skills and attitudes. Continuing medical education and recertification are now theoretically obligatory, to remain working in the same position. Unfortunately, lifelong learning is not generalized among the healthcare professions, even with the increasing development of education technology such as MOOCS (massive open online courses), which normally can help to maintain or strengthen professional competences [20]. However, the career ladders proposed to healthcare workers are not attractive enough to incite them to remain working in the health services. In a survey of 703 health professionals in the United States, 35\% reported that burn-out among physicians was currently a serious problem, while $28 \%$ reported that burnout among nurses also represented a serious problem in their organization [11]. Burn-out can lead to a decline in the quality of care, which negatively impacts on the health system itself in a vicious circle. Moreover, burn-out also partially explains the high rate of attrition, especially among nurses. A survey of 23,000 nurses working in medical and surgical hospital wards in ten EU countries demonstrated that $33 \%$ of nurses intended changing jobs in the next year and $9 \%$ intended to leave the profession [21]. Annual job turnover is estimated to be $6 \%$ for healthcare professionals, and up to $14 \%$ for personal service workers [22].

Considering that in the EU27, the population of over 80 s will increase from $6.1 \%$ in 2020 , to $9.4 \%$ in 2040 , and $12.5 \%$ in 2060 [23], it is high time to raise awareness of the possibilities for attracting and retaining healthcare professionals to cope with the expected future increase in demand for geriatric care. Motivating healthcare professionals is a complex issue and attracting them from other countries is not a solution [24]. Often frustrated by a weak health system, poor infrastructure and living conditions in their country, health care professionals who choose to migrate to higher income countries are drawn by the promise of higher salary and better working conditions. Very often, when they arrive in a new country, their knowledge and skills need to be updated. The greatest problem with health workers migrating from poor to rich countries is the high cost for the poorest countries, who are left facing even greater shortages of health workers [24]. Retention of the healthcare workforce depends mainly on family, cultural and educational factors as well as financial rewards, career development opportunities and continuing education. In addition, the employing organization, the clinical infrastructure and the human organization of the healthcare system also need to be enhanced to be more appealing. Finally, a crucial point in avoiding a major workforce crisis is the urgent need for a profound revision 
of the societal perception of healthcare workers and their value [24].

Once this dramatic Covid 19 pandemic has subsided, we must all fervently hope that politicians and health managers will undertake a thorough update of the healthcare system's organization, and that healthcare professionals will achieve recognition as "heroes", with this upgraded status reflected by an increased salary. These necessary changes will attract ever greater numbers of promising and motivated young persons of both genders into the profession and arm us to deal with the new health challenges the ageing world is forecast to face in the coming decades.

\section{Compliance with ethical standards}

Conflict of interest The authors have no conflict of interest and no funding.

Ethical approval Not applicable.

Informed consent Not applicable.

\section{References}

1. Skills panorama: health and social care. https://skillspanorama. cedefop.europa.eu/en/sectors/health-social-care. Accessed 29 March 2020

2. Healthcare personnel statistics-physicians. https://ec.europ a.eu/eurostat/statistics-explained/index.php/Healthcare_perso nnel_statistics_-_physicians\#Healthcare_personnel. Accessed 29 March 2020

3. Healthcare personnel statistics—nursing and caring professionals. https://ec.europa.eu/eurostat/statistics-explained/index.php?title $=$ Healthcare_personnel_statistics_-_nursing_and_caring_profe ssionals. Accessed 29 March 2020

4. World Health Organization (2016) Global strategy on human resources for health: workforce 2030, Geneva. https://www.who. int/hrh/resources/pub_globstrathrh-2030/en/. Accessed 29 March 2020

5. Liu JX, Goryakin Y, Maeda A, Bruckner T, Scheffler R (2017) Global health workforce labor market projections for 2030. Hum Resour Health 15(1):11

6. Health workforce. https://ec.europa.eu/health/workforce/overv iew_en. Accessed 29 March 2020

7. Woo J (2018) Challenges of population ageing: putting frailty as a cornerstone of health and social care systems. Eur Geriatr Med 9(3):273-276

8. Machón M, Mateo-Abad M, Clerencia-Sierra M et al (2020) Multimorbidity and functional status in older people: a cluster analysis. Eur Geriatr Med 11:321-332. https://doi.org/10.1007/ s41999-020-00291-5
9. Cristina Polidori M (2019) Geriatrics' turning point. Eur Geriatr Med 10(5):681-683

10. Van den Heede K, Bouckaert N, Van de Voorde C (2019) The impact of an ageing population on the required hospital capacity: results from forecast analysis on administrative data. Eur Geriatr Med 10(5):697-705

11. Swensen S, Strongwater S, Seth Mohta N (2018) Leadership survey: immunization against burnout. Catal Carryover 4(2): 15

12. Fellows and Edwards (2016) Future skills and competences of the health workforce in Europe. http://www.healthworkforce.eu, https://healthworkforce.eu/wp-content/uploads/2016/07/JAHWF _WP6_D062-Future-skills-and-competences-of-the-health-workf orce-in-Europe-Final-May-2016.pdf. Accessed 29 March 2020

13. World Health Organization (2016) Working for health and growth: investing in the health workforce. Report of the high-level commission on health employment and economic growth. https:// www.who.int/hrh/com-heeg/reports/en/. Accessed 29 March 2020

14. Lewallen TC, Hunt H, Potts-Datema W, Zaza S, Giles W (2015) The whole school, whole community, whole child model: a new approach for improving educational attainment and healthy development for students. J Sch Health 85(11):729-739

15. de Jong PGM, Pickering JD, Hendriks RA, Swinnerton BJ, Goshtasbpour F, Reinders MEJ (2020) Twelve tips for integrating massive open online course content into classroom teaching. Med Teach 42:393-397

16. Wang R, DeMaria S Jr, Goldberg A, Katz D (2016) A systematic review of serious games in training health care professionals. Simul Healthc 11(1):41-51

17. Cook DA, Triola MM (2009) Virtual patients: a critical literature review and proposed next steps. Med Educ 43(4):303-311

18. Rosen MA, DiazGranados D, Dietz AS, Benishek LE, Thompson D, Pronovost PJ, Weaver SJ (2018) Teamwork in healthcare: key discoveries enabling safer, high-quality care. Am Psychol 73(4):433-450

19. Wang F, Casalino LP, Khullar D (2019) Deep learning in medicine-promise, progress, and challenges. JAMA Intern Med 179(3):293-294

20. Roller-Wirnsberger R, Zitta S, Herzog C, Dornan H, Lindner S, Rehatschek H, Hye F, Kolosovski L, Wirnsberger G, Corsonello A et al (2019) Massive open online courses (MOOCs) for longdistance education in geriatric medicine across Europe. Eur Geriatr Med 10(6):989-994

21. Buchan J, Shaffer FA, Catton H (2018) Policy brief: nurse retention. https://www.icn.ch/sites/default/files/inline-files/2018_ ICNM\%20Nurse\%20retention.pdf. Accessed 29 March 2020

22. Skills panorama: job turnover. https://skillspanorama.cedef op.europa.eu/en/indicators/job-turnover. Accessed 29 March 2020

23. Population structure and ageing. https://ec.europa.eu/eurostat/stati stics-explained/index.php?title=Population_structure_and_agein g. Accessed 29 March 2020

24. Deluca MA, Soucat A (eds) (2013) Transforming the global health workforce. New York University, College of Nursing, New York. https://archive.nyu.edu/handle/2451/31736. Accessed 05 Apr 2020

Publisher's Note Springer Nature remains neutral with regard to jurisdictional claims in published maps and institutional affiliations. 